\title{
Theoretical Implications of Object Clitic Omission in Early French: Spontaneous vs. Elicited Production*
}

\author{
Mihaela Pirvulescu \\ University of Toronto at Mississauga \\ 3359 Mississauga Road North, L5L, 1C6 Canada \\ ma.pirvulescu@utoronto.ca
}

\begin{abstract}
This article examines the phenomenon of object clitic omission in French. Previous research contains contradictory results depending on the source of the data: it seems that in spontaneous production children prefer DPs while in elicited production they prefer omissions. It is proposed that a common methodology be used across different modalities in measuring the rate of omissions, and that the notion of «illicit object omission» be dispensed with. The analysis of the proposed «clitic-contexts» reveals that the strategy favoured by children is omission of all kinds of lexical material in both spontaneous and elicited production. Moreover, it is shown that child behaviour is quantitatively different from the adult one. These findings have consequences on the status of null objects in child grammar: child grammar allows optional object deletion without clitic recoverability, as opposed to adult grammar. Several theoretical approaches are evaluated in the light of the new findings.
\end{abstract}

Key words: object clitic omission, French, spontaneous production, elicited production.

\section{Table of Contents}

\section{Introduction 4. New study}

2. Previous work: 5. Discussion

elicited vs. spontaneous production

References

3. Methodology

\section{Introduction}

The delay in the acquisition of object clitics with respect to other clitic elements has received much attention in the last decade. The phenomenon has been observed for normally developing children (Friedemann 1992, Hamann et al. 1996, Hamann

* I would like to thank Anna Gavarró, Ana Teresa Pérez-Leroux, Yves Roberge and two anonymous reviewers for their comments and suggestions. This research is funded in part by a grant from the Social Sciences and Humanities Research Council of Canada (410-05-0239). 
2003, Jakubowicz et al. 1996, Jakubowicz and Rigaut 2000, van der Velde et al. 2002, Jakubowicz and Nash to appear), SLI children (Hamann et al. in press, Jakubowicz et al. 1998), bilinguals (Hulk 1997, Hulk and Müller 2000, Kaiser 1994) and early L2 (Prévost, ms., Belletti and Hamann 2004, White 1996). Given the extent of the phenomenon, it is important to investigate what strategy the child is using while object clitics have not been (fully) acquired. Thus far, the results obtained for French appear to be dependent on the source of the data, i.e. according to whether one looks at spontaneous or elicited production. I will show that for French this is the result of a difference in the methodology used and I will argue that the strategy favoured by children is omission of all kinds of lexical material. These findings have consequences on the status of null objects in child grammar while clitics are not yet fully acquired: our data points to the fact that child grammar allows free object deletion without clitic recoverability, as opposed to adult grammar. Moreover, there is a period when this option coexists with the target clitic construction. These important findings will be used to evaluate several theoretical approaches that aim to explain the acquisition of object clitics in French.

\section{Previous work: elicited vs. spontaneous production}

In this section I will review the results from both spontaneous and elicited production of French. The picture that emerges is a seemingly contradictory one: while the low rate of clitic production is associated with a high rate of DP use in spontaneous production, it is associated with a high rate of omissions in elicited production.

\subsection{Elicited production}

Elicited production data contain a high rate of omissions. The studies reported in the literature use an elicited production paradigm (Schaeffer 2000): the experimenter asks a question to a puppet introduced as unreliable, and then asks the child to help correct the puppet's factual mistake. The goal of the procedure is to establish the introduced object as the definite topic of the discussion, which is a context where a clitic should be used if one wants to refer to this object again. Constructions with null arguments without identification by clitics are frequent; the children favour null objects over clitics (Jakubowicz et al. 1996, Schmitz et al. 2004, PérezLeroux et al. to appear). An example is provided below:

(1) Question:

Expected answer:

Child's answer:
Qu'est ce que le père fait avec la balle ?

'What is the father doing with the ball?'

Il la frappe. 'He hits it'.

Frappe. 'Hits'. (Nathaniel, 2;8; Pérez-Leroux et al. 2005)

The rate of object omission is high: Jakubowicz et al. $(1996,1997)$ report a rate of 50\% (mean age 2;4); Schmitz et al. (2004) report $44 \%$ omissions (mean age $2 ; 6$ ) and $30 \%$ omissions (mean age $2 ; 10$ ). Pérez-Leroux et al. (in preparation) 
report 35\% omissions (mean age 3;5). The production of DPs is between $30 \%$ and $40 \%$ across the mentioned studies (comparable to the adult DP responses in an elicitation setting) ${ }^{1}$. However, with respect to omissions, the child behaviour contrasts greatly with the adult one: for adults participating in the same elicitation procedure, there were no omissions in the study by Schmitz et al. (2004) which tested four adults, and $4 \%$ omissions in the studies by Pérez-Leroux et al. (to appear, in preparation) where nine adults were tested.

\subsection{Spontaneous production}

Data from spontaneous production points towards a delayed acquisition of object clitics. The low production of object clitics in early French is evaluated with respect to the rate of nominative clitic use, determiners and reflexives ${ }^{2}$. It is shown that during the period where clitics are scarce, children favour DPs: «instead of accusative clitics, the three children produce lexical DPs [...]» (Van der Velde et al. 2002: 122; also Jakubowicz et al. 1996, 1997; Jakubowicz and Rigaut 2000).

The spontaneous data presented in van der Velde et al. (2002) comes from the interaction of three children. These children were recorded in monthly 45- minute sessions. The age of the children ranged between $1 ; 8$ and $2 ; 5$. The omissions are scarce, varying between $10-15 \%$, while the use of DPs rises as high as $70 \%$. Jakubowicz and Rigaut (2000) obtained similar results. They analyzed the production of 12 children from a 45-minute session of spontaneous interaction with each child. The age of the children ranged between 2;0.13 and 2;5.29. Again, the average rate of omissions was around $10 \%$ while the average rate for the lexical nouns was around $70 \%$. The high rate of DP use is surprising given that adults in spontaneous speech seem to use far less: around 34\% from the study by Schmitz et al. (2004).

A higher rate of omission is reported in Hamann $(2002,2003)$ who discusses data from one child, Augustin. The age period studied is from 2;0.2 to 2;9.30. The omissions range from $40 \%$ to $14.4 \%$ in the 10 samples examined. Although the incidence of null objects tends to decline with age, it is still around $20 \%$ in three of the last four samples (between 2;4.22 and 2;9.30). Also, one of the children reported in Jakubowicz and Rigaut (2000) has a rate of $28 \%$ omissions. Therefore, there seem to be different rates of omission even in data coming from spontaneous production alone.

\subsection{The asymmetry}

To recapitulate, there are two sets of data used in evaluating children's acquisition of object clitics. Spontaneous production data, which have a low percentage of

1. Rates of DP production were much lower in other experiments (Schaeffer 2000, Wexler et al. 2004); the source of this contrast remains a topic for future research.

2. «During the development of Augustin's pronominal system subject clitics appeared systematically from the second birthday whereas complement clitics appeared at least 6 months later, which observation lead to the term 'delay' of complement clitics...» (Hamann, 2003:107). 
Table 1.

\begin{tabular}{lll}
\hline & Percentage & References \\
\hline $\begin{array}{l}\text { Object omission } \\
\text { in spontaneous speech }\end{array}$ & $\sim 11 \%$ & $\begin{array}{l}\text { Hulk, 1997, Jakubowicz et al. 1997, } \\
\text { Jakubowicz and Rigaut 2000, van der } \\
\text { Velde 1998, van der Velde et al. 2002 }\end{array}$ \\
\hline $\begin{array}{l}\text { Object omission } \\
\text { in elicited speech }\end{array}$ & $40 \%-60 \%$ & $\begin{array}{c}\text { Jakubowicz et al. 1996, 1997; Schmitz et } \\
\text { al. 2004; Pérez-Leroux et al. 2005 }\end{array}$ \\
\hline
\end{tabular}

omissions, seem to show that the delay in the acquisition of object clitics is compensated by a massive use of DPs. In contrast, elicited production data, which have a high percentage of omissions, show that when children have not yet fully acquired clitics they favour omissions. The picture that thus emerges is that of an asymmetry in object omission in spontaneous versus elicited production. This is summarized in Table 1.

The results obtained in both production procedures show that the child behaviour is strikingly different from the adult one: children use fewer clitics than adults. That being said, the studies differ as to what children use while clitics are not yet produced as in the target. According to the results from spontaneous production, there is an overuse of discourse inappropriate DPs. While under recent theoretical approaches we can expect overlap between the choice of a descriptive DP and a definite pronoun (Farkas 2002), the difference in their rates of use between children and adults indicates a difference at the grammatical level. Similarly, a comparison with the rates of omission found in experimental settings, points towards a grammatical difference between children and adults. In this article I will concentrate on the difference with respect to the rates of omission.

Why do we find such a difference between children's behaviour in spontaneous versus elicited production with respect to the rate of omissions? One possibility, mentioned by Jakubowicz et al. (1996: 384) is that elicited production might have a negative effect on children, such that they tend to omit more objects than during spontaneous interaction: «We believe that the high percentage of object omissions [...] is a by-product of the task itself. If these children assumed that French allowed object deletion, they would have omitted objects also in spontaneous interaction data. As shown [...] this did not happen.» There is, however, another possibility: the low rate of omissions in spontaneous discourse might be a consequence of the methodology used to count these omissions. Therefore, before firmly concluding that the elicitation task favours object omission (which, if true, is an interesting matter to further investigate), we need to look more clearly at the methodology used to calculate object omissions in spontaneous production. 


\section{Methodology}

\subsection{Omissions in spontaneous production}

The calculations of omission phenomena are based on the notion of «obligatory context», and the percentage of omissions in spontaneous speech refers to illicit omissions of the direct object. Illicit object omissions are identified with respect to the adult use: they are cases in which adult speech presumably always shows an overt object. Illicit null object constructions in child production seem to be of three kinds (all examples from Müller 2004 and Müller et al. 1996). First, there are those that violate the lexical transitivity of the verb, as in (2).

\section{(2) Il met _ dans le bain.}

'He puts in the bathtub.'

The example does not come with a description of the linguistic and extralinguistic contexts. It is to be assumed therefore that the verb mettre should obligatorily appear with a lexically realized object.

The second type of illicit construction involves a missing reflexive clitic:

\section{(3) Habille}

dresses

'He puts his clothes on.'

In this case the verb requires an obligatory reflexive object (and a subject).

Finally, the third type of illicit null object construction identified in child speech is the following:

(4) Adult: On peut le manger, l'oeuf?

'Can we eat it, the egg?'

Child: Tu peux manger, oui.

'You can eat, yes.'

We see here an optionally transitive verb used by the child without an overt object or clitic, although there is a definite linguistic antecedent. This would presumably force the use of the clitic in the answer, in order to recover the null object. Therefore, the omission of the clitic in (4), counts also as an illicit omission. However, as it will be shown in section 4.2, one can find ample evidence that similar examples exist also in adult French.

Illicit object omission in spontaneous production therefore seems to encompass a variety of contexts: new information, where a lexical NP would be expected as in (2); reflexives (3); and known information with a definite linguistic antecedent, where a clitic would be expected (4). In elicited production, on the other hand, illicit null objects can be characterized as omissions in the context of known information with a definite linguistic antecedent as in (1) and (4) above. It is therefore necessary to isolate the same type of context in order to be able to com- 
pare children's production of clitics across modalities. In the absence of this, the notion of «illicit» object omission is of no help.

An examination of context was done in Jakubowicz and Rigaut (2000). They found that the omission of a lexical DP was more frequent than the omission of the accusative clitic or the reflexive. Below are examples of each type of omission: lexical DP, reflexive and object clitic (Jakubowicz and Rigaut 2000:137):

(5) a. situation: Claire is putting a piece of the puzzle in its place.

Claire: pas mis (i.e. la pièce)

'Not put' (i.e. the pice of the puzzle)

b. Mother: Qu'est-ce qu'ils font?

'What are they doing?' (she shows an image of two children brushing their teeth)

Child: $\quad$ Ils _ brossent les dents.

'They are brushing the teeth.'

c. Adult: Le lapin de Pâques, tu la connais cette histoire-là?

'The Easter bunny, do you know that story?'

Child: Oui. Je _ connais.

'Yes. I know.'

However, their calculations were based on the total number of constructions with omissions: «In Group 1, among the 12 phrases with a null object, the context indicates that the omitted element is a lexical DP in four cases, a reflexive in 2 sentences and an accusative clitic in one sentence... ${ }^{3}$ These constructions depend on the discourse situation. Therefore, the same shortcomings apply as in the studies mentioned above. What is needed is a calculation of the omission rate versus overt object rate only in the context that requires/permits the use of the clitic. This is shown in the next section.

\subsection{The clitic-context}

It is well known that clitics are not required by verbal transitivity alone, but by a certain discourse situation. The pronominal clitic must be specific, i.e. it must have an antecedent in the preceding discourse (according to the interpretation of the term «specific» provided by Cardinaletti and Starke (1999) and references therein) and, while it can have a token-reading or a type-reading, it must be an entity that can be presupposed (López 2003). Previous studies on spontaneous production seem to have included contexts where clitics are not required as in (6) below (from Van der Velde et al. 2002: 122):

3. «Dans le Group 1, parmi les 12 énoncés à objet nul, le contexte indique que l'élément omis est un DP lexical dans 4 cas, un réfléchi dans 2 énoncés, un clitique accusatif dans 1 énoncé...» (Jakubowicz and Rigaut 2000:137). 
(6) a. situation: Hugo's mother is preparing the animals to construct a farm. Child: je fais une ferme. 'I'm making a farm' Hugo, 2;5.5

b. Adult: tu l'aimes cette chanson? 'Do you like this song?' Child: j'aime Aladdin. 'I like Aladdin.'

Victor, 2;5.29

c. Adult: qu'est-ce que tu veux faire? 'What do you want to do?' Child: je vais pêcher les poissons. 'I am going to catch the fish'

Chloé, 2;4.1

Examples such as those in (6) seem to have been included when deciding what the child is using while clitics are not yet fully acquired. However, the examples (6a) and (6c) are not relevant for this question and should not have been included: the child's behaviour with respect to clitics should only be evaluated in the contexts where the clitic is required or permitted. These are the contexts used in the studies of elicited production.

In the rest of this paper I will concentrate on what I call «clitic contexts», which, in adult speech, cover the clitic-identified null object and the clitic drop. For child spontaneous speech, the clitic context is defined as follows (following Pirvulescu and Roberge 2005) $)^{4}$ : in the clitic-context the referent is definite; it is the topic of the discussion; and it is contained in the immediately preceding discourse.

There are three types of elements, which may appear in the clitic context in children's spontaneous production: clitics, omissions and DPs. An example of each is provided in ( $7 \mathrm{a}-\mathrm{c})$ (from the York corpus, Mona and Para files, CHILDES database):

(7) a. Adult: Elle n'est pas sèche [la pâte à modeler] 'it is not dry.'

Child: Moi va l' couper. 'Me cut it.' Max, 2;2.22

b. Adult: Tu ne veux pas le mettre dans l'eau [le canard]?

'You don't want to put it in the water?'

Child:_ _mettre ici. 'put here' Max, 2;0.14

c. Adult: Voilà la cuillère à Anne.

'Look there is Anne's spoon.'

Child: Willy mange la cuillère à Anne.

'Willy is eating Anne's spoon.'

Anne, $2 ; 4.20$

In the next section I present the new data from spontaneous production available on the CHILDES database as coded and analyzed for the clitic-contexts and the percentage of omissions vs. pronominal clitics. The results from the children are also compared with the results from adult spontaneous child-directed speech.

4. A similar notion is used in Paradis (to appear): a permissible context for direct object pronominalization is one where the referent for the direct object was mentioned within the previous ten lines in the transcript. See also Tsakali and Wexler (2004). 


\section{New study}

In this section I present new data from spontaneous production according to the clitic-context as discussed in the preceding section. The data come from three corpora: two York corpora (the null and clitic counts taken from Pirvulescu, to appear) and the Champaud corpus from the CHILDES database. The three corpora represent the only publicly available recordings that begin from a very early age. The advantage of the York corpora over the Champaud corpus is that in the former the children were recorded more often (every two weeks) and more consistently (the Champaud corpus has time gaps as long as two months). The development of object clitics can therefore be closely followed in the York corpus.

\subsection{Results from spontaneous production}

Tables 2 to 4 show the percentage of null, clitic and lexical objects («Pron» in Table 3 corresponds to $c ̧ a$ «this»).

The three tables show that omission is constant while clitics are not yet (fully) acquired. Moreover, there seems to be a trade-off between the rate of omissions and the rate of clitics: omissions diminish, as clitics are more and more frequently used. On the other hand, the use of DPs seems to be an option children use in an inconsistent way. The results from the first two children show that while the rate of omission is high, the clitics are used optionally. If we look at particular verbs, we can see that the same verb is used either with a clitic, a lexical noun or an omission. Moreover, there are a variety of verbs that are used in this way. An example is provided in (8) from the Para corpus.

Table 2. Corpus Para, France; omissions and overt objects in clitic contexts.

\begin{tabular}{llrrcc}
\hline MLU & AGE & NULL & CL & LEXICAL & Cl contexts (tokens) \\
\hline 2.58 & $2 ; 2.30$ & $62.50 \%$ & $25.00 \%$ & $12.50 \%$ & 8 \\
2.83 & $2 ; 4.2$ & $50.00 \%$ & $16.66 \%$ & $33.00 \%$ & 6 \\
3.01 & $2 ; 4.20$ & $33.33 \%$ & $0.00 \%$ & $66.00 \%$ & 3 \\
2.61 & $2 ; 5.4$ & $25.00 \%$ & $0.00 \%$ & $75.00 \%$ & 4 \\
3.25 & $2 ; 5.18$ & $25.00 \%$ & $37.50 \%$ & $12.50 \%$ & 8 \\
3.38 & $2 ; 6.2$ & $28.00 \%$ & $57.14 \%$ & $14.20 \%$ & 7 \\
3.21 & $2 ; 6.18$ & $70.58 \%$ & $11.76 \%$ & $17.60 \%$ & 5 \\
2.87 & $2 ; 7.1$ & $20.00 \%$ & $60.00 \%$ & $20.00 \%$ & 7 \\
2.85 & $2 ; 8.3$ & $42.85 \%$ & $42.85 \%$ & $14.20 \%$ & 10 \\
3.66 & $2 ; 8.20$ & $40.00 \%$ & $50.00 \%$ & $10.00 \%$ & 2 \\
3.56 & $2 ; 9.15$ & $16.00 \%$ & $83.00 \%$ & $0.00 \%$ & 25 \\
3.59 & $2 ; 10.18$ & $8.00 \%$ & $92.00 \%$ & $0.00 \%$ & \\
\hline
\end{tabular}


Table 3. Corpus Mona, Montréal; omissions and overt objects in clitic contexts.

\begin{tabular}{llrrrrr}
\hline MLU & AGE & NULL & \multicolumn{1}{c}{ CL } & LEXICAL & PRON & Cl contexts (tokens) \\
\hline 1.78 & $2 ; 0.14$ & $50.00 \%$ & $25.00 \%$ & $0.00 \%$ & $25.00 \%$ & 8 \\
1.83 & $2 ; 0.28$ & $40.00 \%$ & $40.00 \%$ & $0.00 \%$ & $20.00 \%$ & 5 \\
2.11 & $2 ; 1.16$ & $40.00 \%$ & $0.00 \%$ & $0.00 \%$ & $20.00 \%$ & 5 \\
2.73 & $2 ; 2.9$ & $27.27 \%$ & $36.36 \%$ & $36.00 \%$ & $0.00 \%$ & 11 \\
2.47 & $2 ; 2.22$ & $40.00 \%$ & $40.00 \%$ & $20.00 \%$ & $0.00 \%$ & 5 \\
2.51 & $2 ; 3.20$ & $57.14 \%$ & $42.85 \%$ & $0.00 \%$ & $0.00 \%$ & 7 \\
2.98 & $2 ; 4.4$ & $20.00 \%$ & $80.00 \%$ & $0.00 \%$ & $0.00 \%$ & 5 \\
3.21 & $2 ; 4.18$ & $16.66 \%$ & $66.66 \%$ & $16.00 \%$ & $0.00 \%$ & 6 \\
3.73 & $2 ; 5.1$ & $27.27 \%$ & $54.54 \%$ & $0.00 \%$ & $0.00 \%$ & 10 \\
3.29 & $2 ; 5.15$ & $20.00 \%$ & $80.00 \%$ & $0.00 \%$ & $0.00 \%$ & 10 \\
3.46 & $2 ; 5.29$ & $0.00 \%$ & $100.00 \%$ & $0.00 \%$ & $0.00 \%$ & 4 \\
3.68 & $2 ; 6.12$ & $33.33 \%$ & $61.11 \%$ & $5.00 \%$ & $0.00 \%$ & 18 \\
\hline
\end{tabular}

Table 4. Corpus Champaud, France; omissions and overt objects in clitic contexts.

\begin{tabular}{llrrrc}
\hline MLU & AGE & NULL & CL & LEXICAL & Cl contexts (tokens) \\
\hline 1.74 & $1 ; 10.20$ & $66.60 \%$ & $0.00 \%$ & $33.30 \%$ & 3 \\
1.86 & $1 ; 11.22$ & $50.00 \%$ & $0.00 \%$ & $50.00 \%$ & 6 \\
2.09 & $2 ; 0.5$ & $33.30 \%$ & $0.00 \%$ & $66.60 \%$ & 6 \\
2.33 & $2 ; 1.25$ & $25.00 \%$ & $0.00 \%$ & $75.00 \%$ & 4 \\
2.55 & $2 ; 3.0$ & $80.00 \%$ & $0.00 \%$ & $20.00 \%$ & 5 \\
3.23 & $2 ; 5.1$ & $0.00 \%$ & $100.00 \%$ & $0.00 \%$ & 10 \\
3.79 & $2 ; 5.13$ & $16.60 \%$ & $66.60 \%$ & $16.60 \%$ & 12 \\
4.7 & $2 ; 5.27$ & $26.30 \%$ & $52.60 \%$ & $21.00 \%$ & 19 \\
\hline
\end{tabular}

(8) a. les mettre 'them put'

b. on met l'oeil 'we put the eye'

c. je mets _ là 'I put there'

(Anne, 2;2.30)

Examples such as (8) show that resort to omissions vs. overt material is not lexically restricted.

\subsection{The nature of omissions with respect to the target}

We can now return to the notion of «illicit omission» discussed in section 3.1.1, where I concluded that in the absence of a well-identified context this notion is not useful. Can we now, after having identified the omissions in the clitic-context, qualify them as illicit from the point of view of the adult grammar? As shown by several authors, comparable omissions exist in the speech of adults (Fónagy, 1985, 
Larjavaara 2000, Lambrecht and Lemoine 2004 among others). Some examples are provided below:

(9) a. A: Voulez-vous que je vous donne mon numéro de téléphone? 'do you want me to give you my phone number?'

B: Non, je connais. 'no, I know (it).'

(Fónagy, 1985:5)

b. A: Tu me le prêtes?

'can you lend them to me?'

B: Bien sûr. Prends!

'of course, take (them)'

(Fónagy, 1985:9)

c. A: Le film il me semble...

'The movie it seems to me...'

B: J'ai pas vu, moi.

'I didn't see (it), me.'

(Lambrecht and Lemoine 2004:26)

Constructions such as (9) seem to be freely available to adults, and the constraints on their use seem to be mainly stylistic or pragmatic. The adult use of this type of construction «results from a choice on the part of the speaker, the null pronoun alternating with an overt lexical or pronominal expression.» (Lambrecht and Lemoine 2004:21). On the surface, the adult constructions in (9) and child construction such as in (10) seem very similar.

(10) a. Adult: tu veux l'essayer, Max?

'do you want to try it, Max?'

Child: moi essayer.

(Max, 2;2.9)

'Me try (it).'

b. Adult: ils [des collants] vont être tout écrabouillés.

'They [the stikers] are going to be crushed.'

Child: Je ramasse, moi.

(Ann, $2 ; 2.30)$

'I pick (them) up, me.'

What should we then qualify as illicit in child language? Awaiting a more detailed analysis of pragmatic, semantic and lexical constraints on those constructions in both child and adult production, it does not seem possible to qualify the child ones as illicit or licit. Moreover, the use of adult judgements does not seem a reliable method in this case. Pirvulescu and Roberge (2005) gave all the instances of object omission in the clitic-context (Champaud corpus) for judgement to four French native speakers. They were asked to judge whether the constructions were grammatical or not. There was a very low rate of agreement among 


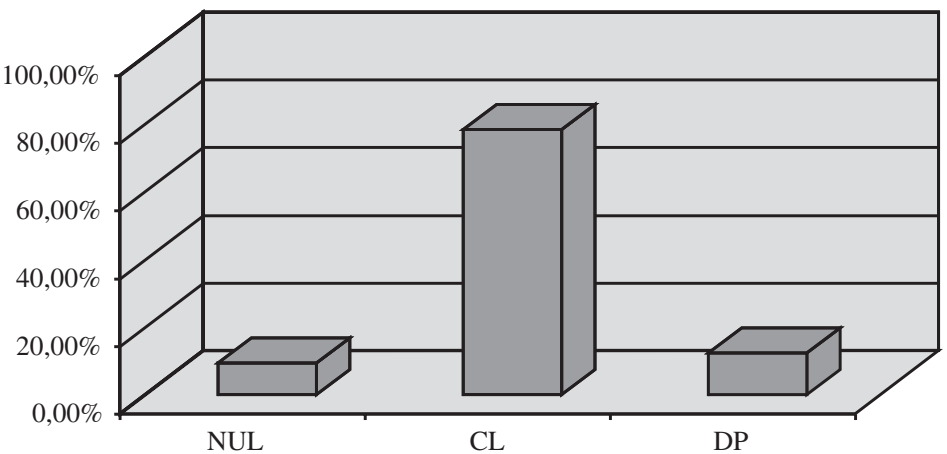

Figure 1. Null objects, clitics and DPs in clitic-context: adult child-directed speech.

those speakers as to what constructions are ungrammatical: all four speakers agreed on only $16 \%$ of the items presented. Therefore, for the time being the only way to compare children's omissions with adults' in spontaneous production is quantitatively, by comparing the rate of omissions in clitic context in adult spontaneous speech with the rate of omissions in children's spontaneous speech.

To the best of our knowledge, there is no quantitative study across adult populations. Therefore, we conducted an analysis of adult child-directed speech data from the York corpora following the same methodology used for the child data. The results are shown in Figure 1.

Figure 1 shows 9.4\% omissions for adults, compared to omissions (at peaks) of $70 \%, 57 \%$ and $80 \%$ respectively for children. There is therefore a substantial quantitative difference between adults and children with respect to omissions. Moreover, Figure 1 also shows that the use of DPs is much lower in adults than in children.

To summarize, the results concerning object omission from child spontaneous production after teasing apart true clitic-contexts from others are now in line with the results from elicitation production. Table 5 presents the comparison between the results from spontaneous production and the results from elicited production.

Table 5. Average rates of omissions in spontaneous and elicited production.

\begin{tabular}{llll}
\hline & Data & Age & NULL(average) \\
\hline \multirow{2}{*}{ Spontaneous production } & Corpus Para & $2 ; 2.30-2 ; 10.18$ & $35.90 \%$ \\
& Corpus Mona & $2 ; 0.14-2 ; 6.12$ & $36.50 \%$ \\
& Corpus Champaud & $1 ; 10.20-2 ; 5.13$ & $37.20 \%$ \\
\hline Elicited production & Jakubowicz et al. (1996, 1997) & $2 ; 4$ (mean) & $50 \%$ \\
& Schmitz et al. (2004) & $2 ; 6$ (mean) & $44 \%$ \\
& Pérez-Leroux et al. (in prep) & $3 ; 5$ (mean) & $35 \%$ \\
\hline
\end{tabular}


Table 5 still shows higher rates of omissions in elicited production. However, the results from spontaneous speech are cumulative and as it can be seen from Tables 2 to 4 the rates of omissions fluctuate from one recording to the other; in some recordings, the rates of omissions are as high or higher than those reported from elicited production. Therefore, we can conclude that the asymmetry between the object omission in spontaneous versus elicited production has been eliminated by using the clitic-context.

\section{Discussion}

The main findings reported in this paper are the following: a) There is an important rate of omissions in a context that requires the use of a clitic (Table 2, 3 and 4). Moreover, the rate of omissions is much higher in children than in adults (Table 2 to 4 and Figure 1). b) By isolating the clitic-context, we are now able to say that the omitted element is indeed the clitic, as it is in the case of elicited production. c) The use of lexical nouns is inconsistent and occurs without correlation to the development of object clitics. The drop in the rate of omissions coincides with the increased frequency of accusative clitics. However, the children use DPs in cliticcontexts at much higher rates than adults in comparable contexts. d) Our data confirm once more that clitics appear gradually and that there is a period where they seem to be optionally used, i.e. they coexist with the omission option.

Results from spontaneous and elicited production therefore converge in that the children produce high rates of omission in the clitic-context. Why are children omitting clitics? Analyses diverge as to whether the child has a problem with the clitic element or with the identification of the null element. The former concentrates on explaining the delay in the appearance of object clitics with respect to other clitic elements while the latter focuses on the omission phenomena. While cross-linguistic examination is necessary for a proper evaluation of the various theories, the data presented help us point out what predictions are not fulfilled in French.

The co-existence of a high rate of omissions with the clitics in the clitic-context clearly presents a challenge for theories proposing that children have a problem with the clitic element (Hamann et al. 1996, van der Velde et al. 2002, Jakubowicz and Nash 1998, 2001, to appear). In one recent proposal, that of Jakubowicz and Nash (to appear), the hypothesis is that children have difficulties merging the clitic in its argument position precisely because the clitic does not conform to the canonical argument. Instead, the children will prefer merging a canonical DP, i.e. a lexical noun. ${ }^{5}$ This approach predicts that when children stop having problems with the merging of a non-canonical argument, they will use, in the appropriate context (the clitic-context), either the clitic or the lexical DP. There is no reason why, once acquired, clitics would be omitted at such high rates. However, we saw that in the

5. However, merging a lexical DP is not always the strategy used by children. Even the data reported in Jakubowicz and Nash (to appear) contain a rate of $15.7 \%$ omissions for 3 year-olds. 
clitic-context, high rates of omission coexist with the use of the clitic. Therefore, the omissions cannot be the result of a problem with the clitic itself. However, this cannot be the whole explanation, since children also use lexical DPs at higher rates than adults. As Jakubowicz (1996) mentioned, this might indicate that young children may not be sensitive to discursive constraints making more felicitous a sentence with a pronoun than with a lexical DP; more research is clearly needed in this area.

High rates of omission could be the result of a wrong parametric choice, as proposed by Müller et al. (1996) and Müller and Hulk (2001), with a free topic drop construction of the Chinese type. However, a parametric approach is tied-up with other characteristics of the initial parametric choice. The null object assumed is a variable and a Chinese-like recoverability mechanism is in place, where the null object is recovered from the discourse through an empty IP-adjoined topic. According to this proposal, the change from a Chinese-type grammar to a Frenchtype grammar is triggered by the lexical instantiation of the $\mathrm{CP}$ domain, which makes the null object (PRO) illicit in the adjoined IP position. However, a correlation between the appearance of lexical elements in the CP field and the appearance of object clitics is hard to establish. A look at the lexical instantiation of the CP domain in the Champaud corpus shows that object clitics appear five months after the lexical instantiation of the CP domain (table 6).

If we consider that at least two elements must be visible in order to assert the lexical instantiation of the $\mathrm{CP}$ field, then this point would be at 2;0.5. When comparing with Table 4, we see that object clitics appear five months after the lexical instantiation of the CP domain. Moreover, Jakubowicz and Rigaut (2000) and van der Velde et al. (2002) report that the children in their study produce all lexical complementizers, while the production of accusative clitics is low. Also, a study comparing the rate of omissions in a comparable experimental task found that Chinese and French children omit objects at different rates (Grüter in progress).

Table 6. The instantiation of the CP field in the Champaud corpus.

\begin{tabular}{lcccccc}
\hline & & Où «Where» & & WH words & Complementizers \\
\hline AGE & MLU & Main sentence & Subordinate & Main sentence & Subordinate & \\
\hline $1 ; 9.18$ & 1.86 & 1 & 0 & 0 & 0 & 0 \\
$1 ; 9.28$ & 1.85 & 1 & 0 & 0 & 0 & 0 \\
$1 ; 10.20$ & 1.74 & 0 & 0 & 0 & 0 & 0 \\
$1 ; 11.22$ & 1.86 & 0 & 0 & 0 & 0 & 0 \\
$2 ; 0.5$ & 2.09 & 5 & 0 & 4 & 0 & 0 \\
$2 ; 1.25$ & 2.33 & 1 & 0 & 1 & 0 & 0 \\
$2 ; 3.0$ & 2.55 & 1 & 0 & 1 & 0 & 0 \\
$2 ; 5.1$ & 3.23 & 1 & 0 & 1 & 0 & 0 \\
$2 ; 5.13$ & 3.79 & 2 & 1 & 4 & 0 & 3 \\
$2 ; 5.27$ & 4.7 & 2 & 0 & 1 & 0 & 2 \\
\hline
\end{tabular}


Even though early French grammar does not seem to be of a topic-drop Chinese type, the data presented in this article clearly indicate that French children do allow object-drop (defined as a null object in the clitic-context, which is not recovered by a clitic). This is in line with the basic observation by Müller et al. (1996) and Müller and Hulk (2001) for bilingual French children ${ }^{6}$. Given the quantitative differences between children and adult rates of omissions, the object-drop in child production seem to result from a different mechanism than the one assumed for adult French (for various analyses proposed for adult French see, among others, Cummins and Roberge (2005), Lambrecht and Lemoine (2004)). Computational approaches that focus either on computational mechanisms (Wexler 1998, Wexler et al. 2003-2004) or on the syntactic representation of the null object (PérezLeroux et al., to appear) in the early grammar might be on the right track in explaining the early French object-drop. On the basis of these data we are not capable of choosing between the two alternatives. Moreover, analyses of object clitic omission need to be evaluated against phenomena such as the omissions/production of other clitic pronouns. This remains a topic for future research.

\section{References}

Belletti, Adriana; Hamann, Cornelia (2004). «On the L2/bilingual acquisition of French by two young children with different source languages». In The acquisition of French in different contexts, ed. by P. Prévost and J. Paradis. John Benjamins: Amsterdam.

Cardinaletti, Anna; Starke, Michal (1999). «The typology of structural deficiency: a case study of the three classes of pronouns». In Clitics in the languages of Europe, ed. by H. van Riemsdijk. Mouton de Gruyter: Berlin.

Cummins, Sarah; Roberge, Yves (2005). «A Modular Account of Null Objects in French». Syntax 8: 44-64.

Farkas, Donka (2002). «Specificity distinctions». Journal of Semantics 19, 213-243. Fonágy, Ivan (1985) «J'aime ?. Je connais ?. Verbes transitifs à objet latent». Revue Romane 20. 3-35.

Friedemann, Marc-Ariel (1992). «The underlying position of external arguments in French», Geneva generative papers 0 (1-2), 123-144.

Grüter, Teres (in progress). Object clitics and null objects in the acquisition of French, Doctoral Thesis in preparation, McGill University.

Hamann, Cornelia (2002). From syntax to discourse. Pronominal clitics, null subjects and infinitives in child language. Kluwer: Dordrecht.

6. The omission rates presented in this article are very similar to those presented by Müller et al. (1996) and Müller and Hulk (2001) for bilingual French-German children. These results indicate that, contrary to what was found in the two mentioned articles, monolinguals use the same type of omissions to the same extent as bilinguals. This would have consequences for the analysis proposed for bilingual French-German children. However, it remains to be seen whether the results are indeed comparable, i.e. based on the same methodology. 
- (2003). «Phenomena in French normal and impaired language acquisition and their implications for hypotheses on language development». Probus 15, 91-122.

Hamann, Cornelia; Rizzi, Luigi; Frauenfelder, Ulrich (1996). «The acquisition of subject and object clitics in French». In Generative Perspectives o Language Acquisition, ed. by H. Clahsen. 309-334, John Benjamins: Amsterdam.

Hamann, Cornelia; Cronel-Ohayon, Stephany; Dubé, Sébastien; Frauenfelder, Ulrich; Rizzi, Luigi; Starke, Michal; Zesinger, Pascal (in press). «Aspects of grammatical development in young French children with SLI». Developmental Science.

Jakubowicz, Celia; Müller, Natascha; Kang, Ok-Kyung; Riemer, Beate; Rigaut, Catherine (1996). «On the acquisition of the pronominal system in French and German». Proceedings of the $20^{\text {th }}$ BUCLD ed. by A. Springfellow, D. Cahana-Amitay, E. Hughes \& A. Zukowski, 374-385. Somerville, Mass.: Cascadilla Press.

Jakubowicz, Celia; Müller, Natascha; Riemer, Beate; Rigaut, Catherine (1997). «The case of subject and object omissions in French and German». Proceedings of the $21^{\text {st }}$ BUCLD ed. by E. Hughes, M. Hughes \& A. Greenhill, 331-342. Somerville, Mass.: Cascadilla Press.

Jakubowicz, Celia; Nash, Lea; Rigaut, Catherine; Christophe-Loic, G. (1998). «Determiners and clitic pronouns in French-speaking children with SLI». Language acquisition 7:113-160.

Jakubowicz, Celia; Rigaut, Catherine (2000). «L'acquisition des clitiques nominatifs et des clitiques objets en français». Canadian Journal of Linguistics 45(1/2), 119157.

Jakubowicz, Celia; Nash, Lea (2001). «Functional categories and syntactic operations in (ab)normal language acquisition». Brain and Language 77, 321-339.

- (to appear). «Why accusative clitics are avoided in normal and impaired language development». In Essays in syntax, morphology and phonology, ed. by C. Jakubowicz, L. Nash and K. Wexler. MIT Press.

Lambrecht, Knud; Lemoine, Kevin (2004). «Definite null objects in (spoken) French.A construction-grammar approach». To appear in Construction Grammar: Back to the Roots, ed. by M. Fried and H. Boas Amsterdam: John Benjamins.

Larjavaara, Meri (2000). Présence ou absence de l'objet. Limites du possible en français contemporain. Helsinki: Academia Scientiarum Fennica.

López, Luis (2003). «Steps for a well-adjusted dislocation». Studia Linguistica 57 (3): 193-231.

Müller, Natascha (2004). «Null-arguments in bilingual children». The acquisition of French in different contexts ed. by P. Prévost and J. Paradis. 275-304. Amsterdam: John Benjamins.

Müller, Natascha; Hulk; Aafke (2001). «Crosslinguistic influence in bilingual language acquisition: Italian and French as recipient languages». Bilingualism: Language and Cognition 4(1). 1-21.

- (2000). «Crosslinguistic influence in bilingual children: object omissions and root infinitives». In Proceedings of the $24^{\text {th }}$ Annual Boston University Conference on Language Development, 546-557, ed. by C. Howell, S. A. Fish and T. Keith-Lucas. Somerville, MA: Cascadilla.

Müller, Natascha; Crysmann, Berthold; Kaiser, Georg A. (1996). «Interactions between the acquisition of French object drop and the development of the C-system». Language Acquisition 5(1). 35-63. 
Pérez-Leroux, Ana; Pirvulescu, Mihaela; Roberge, Yves (to appear). «Early object omission in child French and English». Selected Papers from LSRL 35.

Pérez-Leroux, Ana; Pirvulescu, Mihaela; Roberge, Yves (in preparation). «A syntactic transitivity approach to null objects in child language». Ms. University of Toronto.

Pirvulescu, Mihaela (to appear). «The acquisition of object clitics in French L1: spontaneous vs. elicited production». Proceedings of GALA 2005.

Pirvulescu, Mihaela; Roberge, Yves (2005). «Licit and Illicit Null Objects in L1 French». In Theoretical and Experimental Approaches to Romance Linguistics, ed. by R. Gess \& E. Rubin. 197-212. John Benjamins: Amsterdam.

Schaeffer, Jeannette (2000). The Acquisition of Direct Object Scrambling and Clitic Placement. Amsterdam: John Benjamins.

Schmitz, Katrin; Cantone, Katja; Müller, Natascha; Kupisch, Tanja (2004). «Clitic realizations and omissions in early child grammar: a comparison of Italian and French». Paper delivered at the workshop The Romance Turn, Workshop on the Acquisition of Romance Languages. Madrid, Spain.

Tsakali, Vina; Wexler, Ken (2004). «Why children omit clitics in some languages but not in others: new evidence from Greek». Proceedings of GALA 2003, vol. 2, 493504.

Van der Velde, Marlies; Jakubowicz, Celia; Rigaut, Catherine (2002). «The acquisition of determiner phrase and pronominal clitics by three French-speaking children». Proceedings of the 1999 GALA conference, ed. by I. Lasser, 115-132. Frankfurt am Main: Peter Lang.

Wexler, Kenneth (1998). «Very early parameter setting and the unique checking constraint: a new explanation of the optional infinitive stage». Lingua 106, 23-79.

Wexler, Kenneth; Gavarró, Anna; Torrens, Vicenç (2004). «Feature checking and object clitic omission in child Catalan». In (eds.). Romance Languages and Linguistic Theory 2002, ed. by Bok-Bennema, R., B. Hollebrandse, B. Kampers-Mahne and P. Sleeman. John Benjamins, Amsterdam/Philadelphia, 253-268. 